Tropical Journal of Pharmaceutical Research April 2015; 14 (4): 575-582

ISSN: $1596-5996$ (print); 1596-9827 (electronic)

(C) Pharmacotherapy Group, Faculty of Pharmacy, University of Benin, Benin City, 300001 Nigeria.

All rights reserved.

Available online at http://www.tjpr.org

Original Research Article

http://dx.doi.org/10.4314/tjpr.v14i4.3

\title{
Development and Evaluation of Solid Self Nano- Emulsifying Formulation of Rosuvastatin Calcium for Improved Bioavailability
}

\author{
Nilesh S Kulkarni ${ }^{1 *}$, Nisharani S Ranpise ${ }^{2}$ and Govind Mohan ${ }^{1}$ \\ ${ }^{1}$ Institute of Pharmacy, NIMS University, Jaipur, Rajasthan, ${ }^{2}$ Department of Pharmaceutics, Sinhgad College of Pharmacy, \\ Vadgaon (Bk.), Pune, Maharashtra, India \\ *For correspondence: Email: nileshpcist@gmail.com
}

Received: 16 May 2014

Revised accepted: 28 February 2015

\begin{abstract}
Purpose: To develop rosuvastatin calcium-loaded self-nanoemulsifying powder for improved oral delivery of the drug.

Methods: Solubility study was carried out in different oils, surfactants and co-surfactants. Based on the solubility study, liquid formulations were prepared using LAS/Capryol 90: Maisine 35-1 as oil phase and Tween 20 with Lutrol E400 as surfactant mixture (Smix). The liquid formulations were adsorbed onto Aerosil 200 in a ratio of 1: $0.25 \% \mathrm{w} / \mathrm{w}$ to convert them into a solid form. The formulations were evaluated for globule size, zeta potential, and emulsion properties. Transmittance study, scanning electron microscopy, and in-vitro dissolution studies were carried out. Biochemical studies were carried out using a triton-induced hyperlipidemia model in Wistar rats.

Results: The developed formulations exhibited some desirable characteristics of self-emulsifying systems with nano-sized globules in the range 119.8 to $228.9 \mathrm{~nm}$, rapid emulsification in approximately $60 \mathrm{~s}$ and transmittance of close to $100 \%$. In-vitro dissolution studies on the developed formulations indicate a 4-fold increase in drug release in $10 \mathrm{~min}$, compared to the pure drug (ROC) while pharmacodynamic data showed significant improvement in oral bioavailability compared to the pure drug.

Conclusion: The developed formulation containing the oils, LAS and combination of capryol 90 with Maisine 35-1, has the capability to improve the solubility and bioavailability of rosuvastatin calcium when formulated as a self-nanoemulsifying product.
\end{abstract}

Keywords: Rosuvastatin, Particle size, Zeta potential, Nanoemulsion, Oral bioavailability, Hyperlipidemia, Pharmacodynamics, Surfactants, Co-surfactants

Tropical Journal of Pharmaceutical Research is indexed by Science Citation Index (SciSearch), Scopus, International Pharmaceutical Abstract, Chemical Abstracts, Embase, Index Copernicus, EBSCO, African Index Medicus, JournalSeek, Journal Citation Reports/Science Edition, Directory of Open Access Journals (DOAJ), African Journal Online, Bioline International, Open-J-Gate and Pharmacy Abstracts

\section{INTRODUCTION}

Rosuvastatin calcium (ROC) is a synthetic lipidlowering agent used for oral administration. The IUPAC name of ROC is his $[(E)-7-4(4-$ flurophenyl)-6-isoproyl-2 [methyl (methyl sulfonyl) amino] pyrimidin-5-yl] (3 R, 5 S)-3-5duhydroxyhept-6-enoicacid] calcium salt], which is slightly soluble in water. The available statins have extensive first-pass metabolism [1]. First pass hepatic metabolism is responsible for the poor bioavailability of ROC. Various approaches, includes solid dispersion [2], complexation [3], have been reported to overcome solubility and bioavailability problems. There is increased interest in the development of emulsion type of dosage forms; lipid-based self-micro emulsifying drug delivery system (SMEDDS) is considered to 
be promising technology to improve rate and extent of absorption of poorly or slightly water soluble drugs to improve bioavailability $[4,5]$.

SMEDDS is defined as isotropic mixtures of natural or synthetic oils, surfactants, one or more hydrophilic solvents and co-solvents/surfactants that have a unique ability of forming fine oil-inwater $(\mathrm{o} / \mathrm{w})$ micro emulsions upon mild agitation followed by dilution in aqueous medium and formed emulsion have particle size in the range of 1 to $200 \mathrm{~nm}[6,7]$. Thus, for drugs with solubility and bioavailability issues, these systems may offer the advantages of improvement of rate and extent of absorption, and thus result in improved bioavailability. Since liquid SMEDDS are thermodynamically unstable, to achieve improved stability, self-emulsifying preparations are generally prepared as a solid form [8].

The objective of the study was to prepare a solid self-nanoemulsifying dosage form of ROC to improve its bioavailability using novel, less costly technique, i.e., adsorption to a solid carrier technique

\section{EXPERIMENTAL}

\section{Materials}

Sefsol 228 (propylene glycol dicaprylate) and HCO 40 (PEG 40 hydrogenated castor oil) were received as gifts from Barnet Product Corporation, NJ. Maisine 35-1 (glycerol monolinoleate), Capryol 90 (propylene glycol monocapryl), Cremophore RH 40 (polyoxyl 40 hydrogenated castor oil), Gelucire 44/14 (saturated polyglcolized glycerides) and Lutrol E400 (polyethylene glycol 8) were gifts from BASF, India, LAS (PEG-8-caprylic glycerides), Transcutol, Lauroglycol 90 (propylene glycol monolaurate) were gift samples from Gattefosse India P. Ltd. Captex 200, Captex 355 (triglycerides of caprylic/capric acids) was a gift from Abitech WI. Rosuvastatin calcium was purchased from Balaji Drugs, Surat, India. Olive oil, tween 20, ethyl oleate, propylene glycol and castor oil were analytical grade.

\section{Determination of solubility of rosuvastatin calcium}

Excess amount of ROC was added to $20 \mathrm{ml}$ of distilled water. The suspension was equilibrated on a mechanical shaker for $24 \mathrm{~h}$ at $25^{\circ} \mathrm{C}$ and resulting suspensions were filtered through 0.5 $\mu \mathrm{m}$ Whatman filter paper no. 1 . The filtrate $(0.1$ $\mathrm{ml}$ ) was diluted with $10 \mathrm{ml}$ of distilled water to determine the dissolved amount of ROC using UV visible spectrophotometer (Jasco V-505, Japan) at $241 \mathrm{~nm}$.

\section{Determination of rosuvastatin calcium solubility}

Excess amount of ROC was added to $3 \mathrm{ml}$ of different oils (Sefsol 228, HCO 40, Maisine 35-1, LAS, ethyl oleate, olive oil, castor oil, Capryol 90, Gelucire 44/14), surfactants (Tween 20, Lauroglycol and Cremophore $\mathrm{RH} 40$ ) and cosurfactants (Lutrol E-400, propylene glycol and Transcutol). In each case, the suspension was sonicated for $15 \mathrm{~min}$ and heated on a water bath maintained at $40{ }^{\circ} \mathrm{C}$ to allow solubilization of ROC. The resulting suspension was agitated on a rotary shaker for $24 \mathrm{~h}$ to achieve equilibration. Thereafter, the suspension was centrifuged at $4000 \mathrm{rpm}$ for $15 \mathrm{~min}$. The supernatant suitably diluted with methanol and the dissolved concentration of ROC was determined spectrophotometrically at $241 \mathrm{~nm}$.

\section{Identification of micro-emulsion region}

From the solubility study, oil, surfactant and cosurfactant were selected to construct a pseudo ternary phase diagram. Maisine 35-1, Capryol 90 , LAS were selected as oil phase; Tween 20 and Lutrol E 400 were selected as surfactant and co-surfactants respectively. From pseudo-ternary phase diagram, a stable micro-emulsion zone was identified. For the identification of a micro emulsion zone, surfactant to co-surfactant ratio (Smix) was kept at 1:1. The Smix concentration was increased from 1 to 9 by keeping oil phase as constant. Oil and surfactant mixture were mixed at a ratio of 1:1, 1:2, 1:3, 1:4, 1:5, 1:6, 1:7, $1: 8$ and $1: 9$, respectively.

Furthermore, study was carried out by keeping Smix as constant 1:1. Oil and surfactant mixture was mixed at a ratio of $1: 1,2: 1,3: 1,4: 1$, respectively [9]. To each of the mixture distilled water was added drop wise until the first sign of turbidity occurred; the solution was allowed to equilibrate and if turbidity changed to a clear solution again, excess amount of water was added to the observed turbidity.

\section{Preparation of liquid L-SMEDDS and S- SMEDDS}

Based on the phase diagram, oil and Smix ratio were selected as vehicle at which wide micro emulsion region is observed were selected as the vehicle for the formulation of L-SMEDDS. ROC was added to the oil phase and sonicated for $10 \mathrm{~min}$. To it, surfactant and co-surfactant 
were added in the proportions shown in Table 1. The resultant mixtures were heated over a water bath maintained at $40^{\circ} \mathrm{C}$ for $10 \mathrm{~min}$ to facilitate solubilization of ROC, and vortexed for $15 \mathrm{~min}$ until ROC was completely dissolved.

\section{Conversion of Liquid-SMEDDS to Solid- SMEDDS}

Based on the preliminary evaluation, liquid formulations containing LAS/ Capryol 90: Maisine 35-1 with Tween 20: Lutrol E 400 was selected for convertion into solid formulation.

S-SMEDD system was prepared by addition of LSMEDD to aerosil-200 in 1:0.25 \% w/w proportion. L-SMEDDS was added drop wise onto aerosil-200 in a porcelain dish to get uniform distribution of drug and dried at room temperature.

\section{Evaluation of L-SMEDDS and S-SMEDDS}

\section{Drug content}

L-SMEDDS ( $\mathrm{L} 1$ to $\mathrm{L} 4$ ) and S-SMEDDS ( $\mathrm{S} 1$ and $S$ 2) equivalent to $10 \mathrm{mg}$ were dissolved in $10 \mathrm{ml}$ of methanol in $10 \mathrm{ml}$ volumetric flask separately and suitably diluted with methanol to determine ROC content at $241 \mathrm{~nm}$ spectrophotometerically.

\section{Assessment of transmittance and reconstitution}

L-SMEDDS ( $\mathrm{L} 1$ to $\mathrm{L} 4$ ) and S-SMEDDS (S 1 and $S$ 2) formulations (equivalent to $10 \mathrm{mg}$ of $\mathrm{ROC}$ ) were diluted with $100 \mathrm{ml}$ of distilled water maintained at $37 \pm 2{ }^{\circ} \mathrm{C}$ and content was mixed gently using magnetic stirrer, and emulsion droplet size was observed with respect to time. Reconstitution property was evaluated qualitatively as good when clear microemulsion formed, or bad, if turbid or milky emulsion formed after cessation of stirring. For the resultant solutions, percent transmittance was determined spectrophotometrically at $638.2 \mathrm{~nm}$ using distilled water as blank.

\section{Assessment of self-emulsification and precipitation}

It was performed by drop wise addition of preconcentrate (L-SMEDDS), One $\mathrm{ml}$ of formulation was added to $250 \mathrm{ml}$ of distilled water maintained at $37 \pm 0.5{ }^{\circ} \mathrm{C}$ with stirring of $50 \mathrm{rpm}$. Precipitation was evaluated by visual inspection of resulting emulsion after $24 \mathrm{~h}$. Based on precipitation study; formulations were categorized as Grade A Clear (transparent or transparent with bluish tinge), Grade B not clear (turbid), Grade C Stable (no precipitation at the end of $24 \mathrm{~h}$ ), Grade D Unstable (showing precipitation within $24 \mathrm{~h}$ ).

\section{Robustness to dilution}

L-SMEDDS (L 1 to $L$ 4) and S-SMEDDS (S 1 and $S$ 2) formulations (equivalent to $10 \mathrm{mg}$ of ROC) were added to $100 \mathrm{ml}$ of distilled water. The resulting solutions were observed for phase separation for $12 \mathrm{~h}$ and $24 \mathrm{~h}$.

\section{In vitro dissolution studies of L-SMEDDS and S-SMEDDS}

In-vitro dissolution study was carried out using USP type II apparatus operated at $50 \mathrm{rpm}$. LSMEDDS and S-SMEDDS containing $10 \mathrm{mg}$ equivalent of ROC and plain ROC were filled in size 0 capsule shells. The capsule was added to $900 \mathrm{ml}$ of distilled water as dissolution medium maintained at $37 \pm 0.5{ }^{\circ} \mathrm{C}$. Aliquots $(10 \mathrm{ml})$ were withdrawn at predetermined time intervals for 60 min and analyzed for dissolved ROC content spectrophotometrically at $241 \mathrm{~nm}$.

\section{Particle size and zeta potential measurement}

One $\mathrm{ml}$ (Equivalent to $10 \mathrm{mg}$ ) of L-SMEDDS containing LAS, Capryol 90: Maisine 35-1 and 10 mg equivalent of S-SMEDDS containing LAS, Capryol 90: Maisine 35-1 were diluted/ reconstituted with $100 \mathrm{ml}$ of distilled water.

Table 1: Composition of L-SMEDDS and S-SMEDDS

\begin{tabular}{|c|c|c|c|c|c|c|c|}
\hline Formulation & $\begin{array}{l}\text { Rosuvastatin } \\
\text { calcium } \\
\text { (mg) }\end{array}$ & $\begin{array}{c}\text { Maisine 35-1 } \\
\text { (\%) }\end{array}$ & $\begin{array}{c}\text { Capryol } \\
90(\%)\end{array}$ & $\begin{array}{c}\text { Maisine:35-1: } \\
\text { Capryol } 90 \\
(\%)\end{array}$ & $\begin{array}{l}\text { LAS } \\
(\%)\end{array}$ & $\begin{array}{l}\text { Tween } \\
20 \text { (\%) }\end{array}$ & $\begin{array}{c}\text { Lutro } \\
\text { E 400 } \\
(\%)\end{array}$ \\
\hline$\overline{\mathrm{L} 1}$ & 1000 & 15 & - & - & - & 21 & 21 \\
\hline L 2 & 1000 & - & 15 & - & - & 25 & 25 \\
\hline L3 & 1000 & - & - & 15 & - & 21 & 21 \\
\hline L 4 & 1000 & - & - & - & 48 & 11 & 11 \\
\hline S 1 & 1000 & & & & 48 & 11 & 11 \\
\hline S 2 & 1000 & & & 15 & - & 21 & 21 \\
\hline
\end{tabular}


The resulting emulsions were subjected to determination of globule size and zeta potential respectively using malvern zetasizer.

\section{Scanning electron microscopy}

The surface morphology of S-SMEDDS containing LAS as well as plain ROC powder were investigated by S-4100 scanning electron microscope ( S-4100 Hitachi, Japan) at $500 \mathrm{X}$ at $5 \mathrm{kv}$.

\section{Biochemical studies}

The protocol of the animal study was approved by the institutional animal ethical committee (IAEC Protocol Approval no. 1036/a/07/ CPCESA/IAEC/12-13/E-4). The animals were handled and maintained as per the guidelines provided by Committee for the Purpose of Control and Supervision on Experiments on Animals, and also Organization for Economic Cooperation and Development (OECD) guidelines were adhered to the study [10].

The test sought to compare the lipid lowering potential of ROC in L-SMEDDS and S-SMEDDS formulations. Triton-induced hyperlipidemia model in Wistar rats was used. The lipid lowering potential of plain ROC was compared with LSMEDDS and S-SMEDDS formulations.

The animals were divided into seven groups of six animals each as follows: Group I - normal, Group II - control, Group III - L-SMEDDS containing Maisine 35-1: Capryol 90 as oil (L 3), Group IV - L-SMEDDS containing LAS as oil (L 4), Group V - plain ROC, and Group VI - SSMEDDS containing Maisine 35-1: Capryol 90 (S 2), and Group VII - S-SMEDDS containing LAS ( $S 1)$.

Triton X $100(100 \mathrm{mg} / \mathrm{kg})$ was administered intraperitoneally to each animal. Blood samples were withdrawn after $72 \mathrm{~h}$ after triton injection by retro orbital route under light ether anesthesia and analyzed for total cholesterol (TC), total triglycerides (TG), high density lipoprotein (HDL), low density lipoprotein (LDL) and very low density lipoprotein (V-LDL) using a diagnostic kit provided by Accozyme (India).

After that dose equivalent to $10 \mathrm{mg} / \mathrm{kg}$ were administered to groups I, II to VII respectively. The blood samples were withdrawn after $24 \mathrm{~h}$ and analyzed for TC, TG, HDL and V-LDL concentration. The comparison was carried out between the control and test groups [11].

\section{Statistical analysis}

All values were expressed as a mean \pm standard deviation ( $S D, n=3)$. Comparison between the groups was made by one-way analysis of variance (ANOVA) followed by Turkey's test using Graph Pad Instat version 2008. Differences between groups were considered significant at $p$ $<0.05$.

\section{RESULTS}

\section{Solubility of rosuvastatin calcium}

The solubility of ROC was $0.32 \mathrm{mg} / \mathrm{ml}$ in distilled water.

\section{Solubility of rosuvastatin calcium in various liquids}

Maisine 35-1, Capryol 90 and LAS showed highest solubilizing capacity for rosuvastatin calcium (Table 2).

Table 2: Solubility of rosuvastatin calcium in different oils (mean, $n=3$ )

\begin{tabular}{lc}
\hline Oils & $\begin{array}{c}\text { Solubility } \\
\text { (mg/ml) }\end{array}$ \\
\hline Maisine 35-1 & 57.43 \\
Capryol 90 & 27.33 \\
LAS & 44.22 \\
Gelucire 44/14 & 18.34 \\
Sefsol 228 & 0.40 \\
HCO 40 & 8.56 \\
Castor oil & 0.78 \\
Olive oil & 7.08 \\
Ethyl oleate & 1.30 \\
Captex 200 & 0.049 \\
Captex 355 & 0.21 \\
\hline
\end{tabular}

Among surfactants, Tween 20 showed highest solubility $(32.15 \mathrm{mg} / \mathrm{ml})$ whereas solubility in lauroglycol $(11.72 \mathrm{mg} / \mathrm{ml})$ and Cremophore $\mathrm{RH}$ $40(6.16 \mathrm{mg} / \mathrm{ml})$ was found to be insignificant. Among co-surfactants, Lutrol E-400 showed highest solubility of $75.59 \mathrm{mg} / \mathrm{ml}$ whereas solubility in transcutol and propylene glycol was found to be $68.65 \mathrm{mg} / \mathrm{ml}$ and $23.72 \mathrm{mg} / \mathrm{ml}$ respectively.

\section{Identification of micro-emulsion zone}

Self-microemulsifying system form fine oil in water emulsion upon gentle agitation when added to aqueous medium. Surfactant and cosurfactant gets preferentially adsorbed at interface, reducing the interfacial energy as well as providing mechanical barrier for coalescence. 

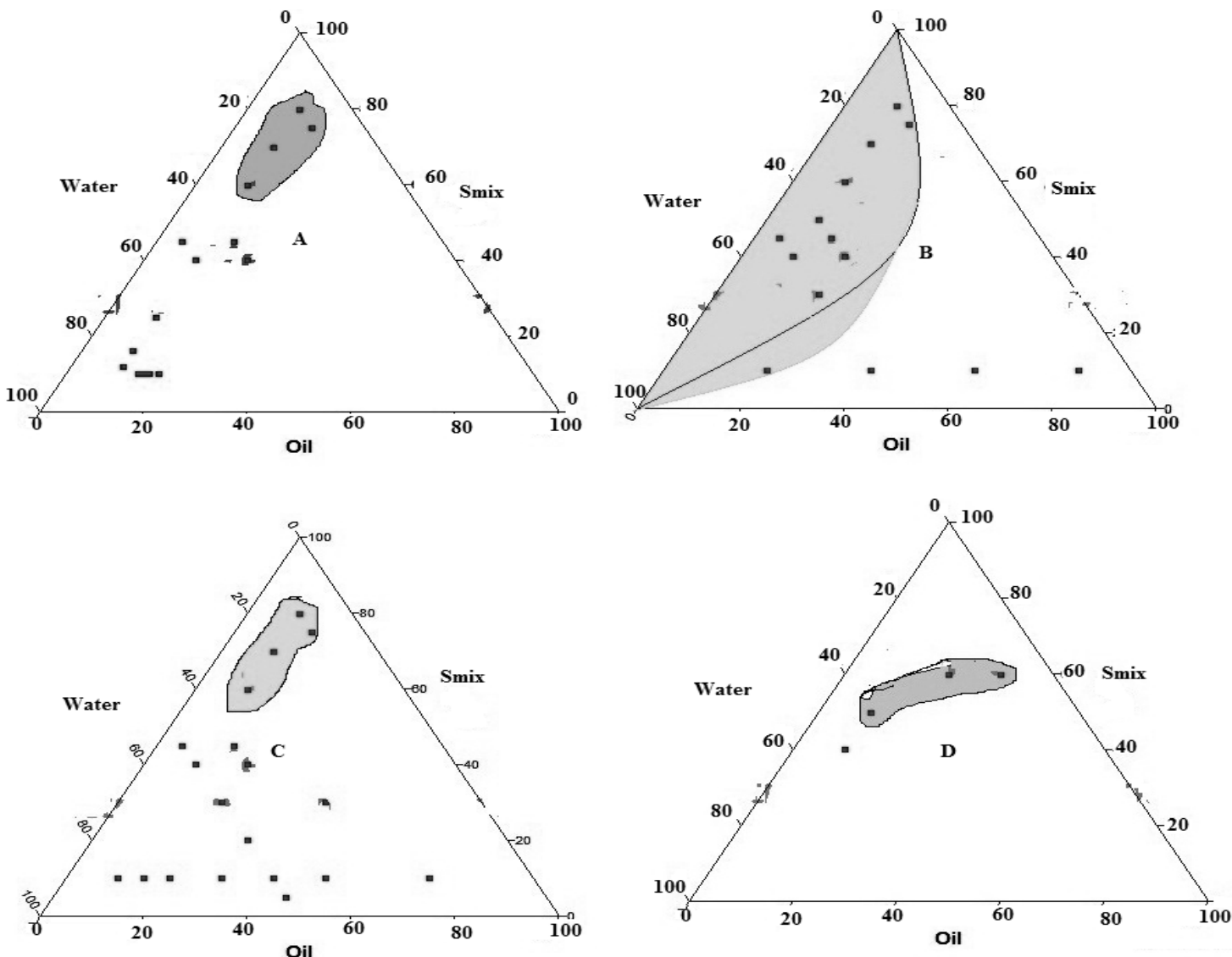

Figure 1: Pseudo-ternary phase diagrams. $A=$ Maisine 35-1, B = LAS, C = Capryol 90, D = Capryol 90: Maisine 35-1 as oil phase with Tween 20 and Lutrol E 400 as surfactant and co-surfactant at Smix ratio of 1:1 (mean $n=$ 3)

As seen from the ternary plot (Figure 1), LAS gave a wider microemulsion region as compared to Capryol 90 and Maisine 35-1. Combinations of Capryol 90 and Maisine 35-1 resulted into increased oil concentration as that of individual oil. Thus LAS and Capryol 90: Maisine 35-1 were preferred vehicle with Tween 20 and Lutrol E 400 as surfactant and co-surfactant, respectively, for development of formulation. Based on the pseudo ternary phase diagram formulation were selected which has less \% w/w concentration of Smix and greater $\% \mathrm{w} / \mathrm{w}$ of oil phase.

\section{L-SMEDDS and S-SMEDDS characteristics}

\section{Drug content}

The drug content of all the formulation was in the range of 95 to $105 \%$.
Transmittance of L-SMEDDS and S-SMEDDS, and reconstitution of S-SMEDDS

The transmittance values of L3, L4, S1 and S2 formulation above $90 \%$ confirming the selfnanoemulsifying eficiencey of SMEDDS (Table 3). The reconstitution of solid formulations was found to be spontaneous micro emulsification upon stirring and it was observed within $60 \mathrm{sec}$ upon reconstitution and no sign of precipitation and milky appearance for the formed emulsion.

\section{Self-emulsification and precipitation assessment}

Among the liquid formulations $\mathrm{L} 1$ to $\mathrm{L} 4$, formulations $L 3$ and $L 4$ exhibited grade $A$ type

Table 3: Drug content and transmittance of L-SMEDDS and S-SMEDDS (Mean, $n=3$ )

\begin{tabular}{lcccccc}
\hline Test Parameters & \multicolumn{7}{c}{ SMEDDS } \\
\cline { 2 - 7 } & L1 & L2 & L3 & L4 & S1 & S2 \\
\hline Drug Content $^{*}$ & 98.24 & 99.26 & 99.38 & 100.23 & 100.13 & 99.23 \\
Percentage of & 86.29 & 87.12 & 90.34 & 99.12 & 98.23 & 96.29 \\
Transmittance $^{*}$ & & & & &
\end{tabular}


of emulsion with self-emulsification time less than 1 min, whereas $L 1$ and $L 2$ formulation were categorized as grade $\mathrm{D}$.

\section{Robustness to dilution}

No phase separation was observed for preparations $L 3, L 4, S 1, S 2$ at the end of $24 \mathrm{~h}$ in distilled water whereas $L \quad 1$ and $L \quad 2$ formulations showed precipitation after $12 \mathrm{~h}$.

\section{In-vitro dissolution profile}

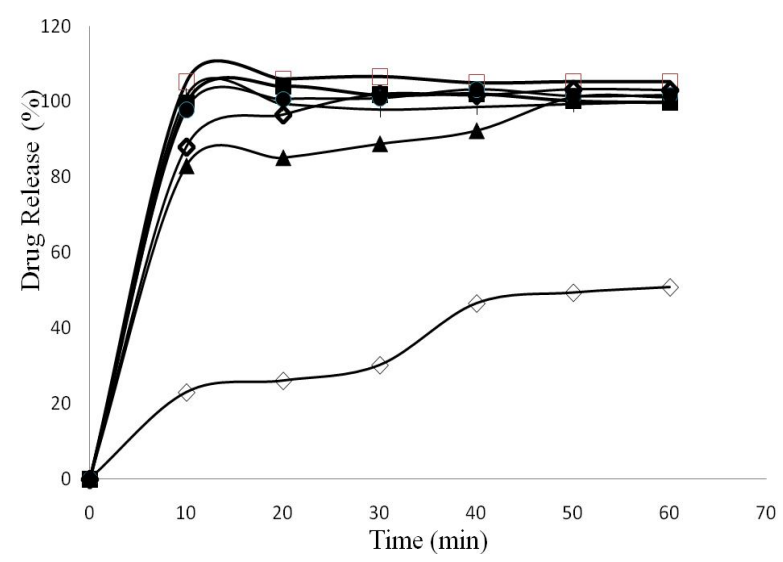

Figure 2: In-vitro dissolution profile. $\diamond=$ plain ROC, $\bullet$ $=\mathrm{L} 1$ Formulation, $+=\mathrm{L} 2$ formulation, $\mathbf{\square}=13$ formulation, $\square=\mid 4$ formulation, $\diamond=\mathrm{s} 1$ formulation, $\Delta$ $=\mathrm{s} 2$ formulation (mean $\pm \mathrm{SD}, \mathrm{n}=3$ )

The dissolution study showed that plain ROC showed poor release profile when compared to L-SMEDDS and S-SMEDDS. At the end of 60 min, $40 \%$ of the drug was dissolved whereas more than $90 \%$ drug was dissolved in distilled water from L-SMEDDS and S-SMEDDS formulations containing LAS and Capryol 90: Maisine 35-1 as oil (Figure 2).

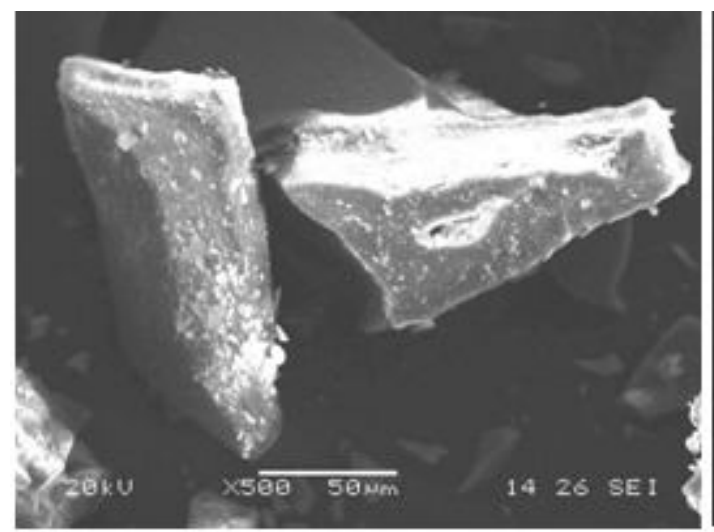

$\mathbf{x}$

\section{Globule size and zeta potential}

For L3, L 4, S 1 and S 2 had z-average globule size diameter of $146.1,119.8,213.2$ and 228.9 $\mathrm{nm}$, respectively. Zeta potential of the formulations was found to be $-4.93,-9.14,-8.06$ and -11.8 respectively. As $L 1$ and $L 2$ were categorized as unstable formulation and categorized as grade $D$ formulation so they are excluded from the study.

\section{Morphology of ROC and S-SMEDDS}

The SEM micrograph of ROC and S-SMEDDS containing LAS were shown in Figure 3. The micrograph of Plain Rosuvastatin calcium appeared as crystalline (Figure 3, Part X). The SEM images of solid SMEDDS showed wellseparated particles with no agglomeration (Figure 3, Part Y).

\section{Lipid profile}

Triton is a non-ionic detergent that inhibits lipoprotein lipase; therefore it raises levels of serum lipids in experimental animals. A single injection of triton (100 mg/kg, i.p.) elevated TC, TG, LDL and V-LDL levels 2-fold, respectively, compared with the untreated group, whereas high density lipoprotein level decreased by up to $50 \%$ in all groups, compared to an untreated control group ( $p>0.05$, Table 4).

At the end of $24 \mathrm{~h}$ of dosing, reduction in TC, TG, LDL and $\mathrm{V}$-LDL levels was observed in all groups except normal group. Formulations containing LAS as oil showed greater reduction in elevated level of TC, TG, LDL and VLDL $(p>0.05$, Table 4) compared to the formulations containing Maisine 35-1: Capryol 90 as oil.

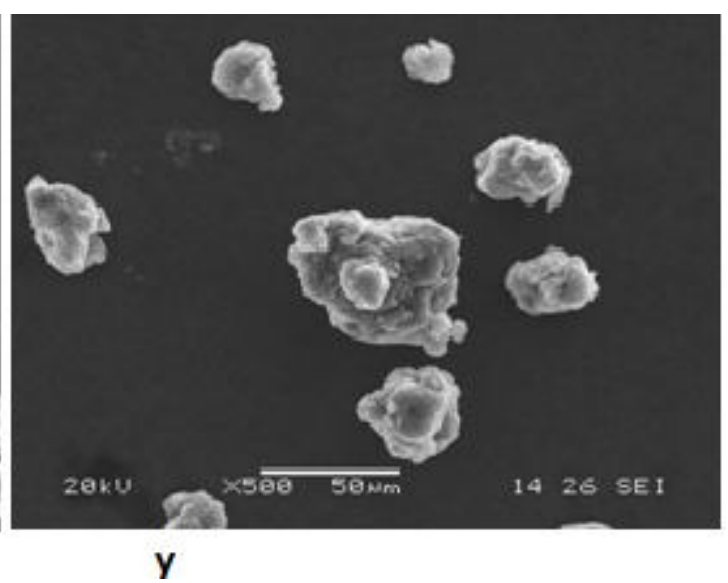

Figure 3: Scanning electron micrograph of ROC (X) and S-SMEDDS containing LAS (Y) 
Table 4: Blood TC, TG, HDL, LDL, V- LDL levels of groups after $72 \mathrm{~h}$ of Triton injection

\begin{tabular}{clccccc}
\hline Group & Treatment & TC & TG & HDL & LDL & VLDL \\
\hline I & Normal & $69.79 \pm 3.31$ & $126.75 \pm 4.2$ & $34.39 \pm 1.14$ & $82.84 \pm 2.83$ & $28.66 \pm 1.91$ \\
II & Control & $131.77 \pm 2.6$ & $184.41 \pm 8.8$ & $17.34 \pm 2.26$ & $139.68 \pm 2.31$ & $75.16 \pm 4.92$ \\
III & L 3 & $129.46 \pm 3.02$ & $188.69 \pm 4.92$ & $17.87 \pm 2.01$ & $138.29 \pm 2.54$ & $70.32 \pm 4.68$ \\
IV & L 4 & $132.04 \pm 3.62$ & $196.15 \pm 4.49$ & $16.8 \pm 2.4$ & $142.66 \pm 3.17$ & $73.43 \pm 3.86$ \\
V & ROC & $132.47 \pm 2.45$ & $193.19 \pm 3.15$ & $17.54 \pm 5.45$ & $138.7 \pm 0.89$ & $74.97 \pm 0.48$ \\
VI & S 2 & $133.18 \pm 6.28$ & $187.59 \pm 4.79$ & $18.72 \pm 1.99$ & $139.1 \pm 2.72$ & $74.46 \pm 3.87$ \\
VII & S 1 & $130.72 \pm 3.7$ & $193.63 \pm 5.67$ & $19.19 \pm 2.94$ & $137.76 \pm 4.79$ & $74.97 \pm 4.62$ \\
\hline
\end{tabular}

Table 5: Blood TC, TG, HDL, LDL, V- LDL levels of groups after $24 \mathrm{~h}$ of administration of ROC dose

\begin{tabular}{|c|c|c|c|c|c|c|}
\hline Group & Treatment & TC & $\overline{T G}$ & HDL & $\overline{\mathrm{LDL}}$ & VLDL \\
\hline $\mathrm{I}$ & Normal & $77.81 \pm 2.86$ & $120.86 \pm 3.48$ & $35.64 \pm 2.78$ & $75.31 \pm 4.93$ & $25.87 \pm 2.41$ \\
\hline II & Control & $131.51 \pm 2.47^{\mathrm{C}}$ & $174.3 \pm 8.21^{\mathrm{C}}$ & $16.24 \pm 1.9^{c}$ & $153.72 \pm 4.77^{\mathrm{C}}$ & $64.47 \pm 2.01^{\mathrm{c}}$ \\
\hline III & L 3 & $75.86 \pm 3.82^{\dagger, 1}$ & $120.8 \pm 2.92^{, 1,1}$ & $39.01 \pm 1.3 \mathrm{~s} 5^{\dagger}$ & $92.81 \pm 6.09^{t, k}$ & $25.76 \pm 2.18^{\dagger, k}$ \\
\hline IV & L 4 & $62.57 \pm 3.06^{\dagger, 1}$ & $114.53 \pm 2.82^{\dagger, l}$ & $39.44 \pm 5.02^{\dagger}$ & $77.72 \pm 7.71^{\mathrm{t}, \mathrm{l}}$ & $22.72 \pm 1.04^{\mathrm{t}, \mathrm{k}}$ \\
\hline V & ROC & $108.69 \pm 5.5^{\mathrm{e}}$ & $144.32 \pm 3.9^{\mathrm{e}}$ & $36.03 \pm 2.85^{e}$ & $120.72 \pm 2.83^{\mathrm{e}}$ & $45.45 \pm 6.13^{\mathrm{e}}$ \\
\hline VI & S 2 & $80.56 \pm 2.62^{\mathrm{t}, \mathrm{l}}$ & $122.2 \pm 2.9^{\mathrm{t}, \mathrm{l}, \mathrm{l}}$ & $38.5 \pm 4.16^{\dagger}$ & $93.14 \pm 6.00^{t, 1}$ & $26.45 \pm 2.89^{\mathrm{t}, \mathrm{k}}$ \\
\hline VII & S 1 & $65.78 \pm 2.85^{\mathrm{t}, \mathrm{l}}$ & $117.42 \pm 4.51^{\mathrm{t}, \mathrm{l}}$ & $38.38 \pm 3.24^{\dagger}$ & $80.69 \pm 4.74^{\dagger, ।}$ & $22.45 \pm 2.04^{\dagger, l}$ \\
\hline
\end{tabular}

\section{DISCUSSION}

All formulations of liquid and solid nanoemulsifying system with ROC gave stable clear micro emulsion region.

Drug content, which was in the range of 95 to $105 \%$, indicates good drug distribution in the selected vehicle. Transmittance values, being 90 to $100 \%$, indicate the micro emulsion was virtually transparent. With regard to emulsification, precipitation and robustness to dilution, precipitation was observed within $24 \mathrm{~h}$ for $L 1$ and $L 2$ formulations, and this may be attributed to the high concentration of surfactants in the formulations, indicates formulations are not stable. On the contrary, for L 3, L 4, S 1 and S 2 formulations, no precipitation was observed for $24 \mathrm{~h}$. It indicates developed formulations were stable. Rapid reconstitution is required for the rapid absorption of drug from gastrointestinal environment. The solid formulations S 1 and S 2 showed rapid emulsification time of $<90 \mathrm{sec}$, which may lead to improved absorption of ROC from gastrointestinal tract since the drug is available in submicron size.

In-vitro dissolution data showed improvement in ROC solubility for all formulations compared with plain ROC. This may be attributed to increase in effective surface area through reduction in the mean diameter of globule size.

Globule sizes of formulations were in nano-meter range for formulations $L 3, L 4, S 1$ and $S 2$. The globule size of the emulsion is an important factor in self-emulsification process because it determines rate and extent of drug dissolution and absorption of drug. The charge on the droplet is the property determined for assessment of absorption. The zeta potential for the $L 3, L 4, S 1$ and $S 2$ is negative; it is because of presence of fatty acids, it confirms formed emulsion is nano emulsion and was stable. The reported value of formulations was in negative between -4.93 to -11.8 . The absolute value of zeta potential was lower than those values reported in the literature. This might be attributed to tween 20 and lutrol E 400, non-ionic surfactants which decreases the electrostatic repulsion between the particles and sterically stabilizes the system by forming a coat around their surface [12]. The SEM micrograph showed crystalline nature of ROC. It is not observed in solid SMEDDS micrograph suggesting that the drug is completely solubilized in a solid SMEDDS.

Clinical studies have demonstrated that ROC is the most effective drug in reducing low-density lipoprotein cholesterol [13].

Statins also have beneficial effects on other lipid parameters, including increase in high-density lipoprotein cholesterol levels and decrease in triglyceride levels, and are predominantly metabolized by cytochrome P450 [14]. Mixture of Capryol 90: Maisine 35-1 and LAS as oil phase respectively has the capability to minimize variability in absorption as well as to avoid first pass metabolism of ROC as it could produce more uniform drug concentration in the systemic circulation and avoids first pass metabolism, 
which leads to improvement in bioavailability [15].

\section{CONCLUSION}

An optimized self-nanoemulsifying formulation consisting of a mixture of Capryol 90: Maisine 35-1/ LAS as the oil phase with Tween 20: Lutrol 400 as surfactant exhibits spontaneous emulsification properties. The formulation shows better in-vitro release profile as well as superior lipid-lowering potential than plain ROC. Futhermore, Aerosil 200 is an effective carrier with high drug loading capacity for the administration of liquid drugs in solid dosage form.

\section{ACKNOWLEDGEMENT}

The authors are thankful to Gattefose India Pvt Ltd, India, BASF India, Barnet Product Corporation, NJ and Abitech WI, USA for the gift of materials used in the study. They are also thankful to Chairman, P. E. Society and Principal, Modern college of Pharmacy (for Ladies), Moshi, Pune, India for providing research facility.

\section{REFERENCES}

1. Schachter M. Chemical, pharmacokinetic and pharmacodynamics properties of statins: an update, Fundamental \& Clinical Pharmacology, Blackwell Publishing, 2004: pp 117-125.

2. Dehghan M. Mohammad J. Improving dissolution of meloxicam using solid Dispersions, Iran. J. Pharm. Res., 2006; 4: 231-238.

3. Ranpise NS, Kulkarni NS, Mair PD. Improvement in water solubility and in vitro dissolution rate of aceclofenac by complexation with $\beta$-cyclodextrin and hydroxypropyl $\beta$-cyclodextrin, Pharm. Dev. Tech., 2010; 15 (1): 64-70.

4. Chakraborty S, Shukla D, Brahmeshwar M, Singh S. Lipid - An emerging platform for oral delivery of drugs with poor bioavailability, Eur J. Pharm. Biopharm., 2009; 73: 1-15.
5. Vavia PR. Preparation and in vivo Evaluation of Selfmicroemulsifying Drug Delivery System Containing Fenofibrate. AAPS J. 2007; 9 (3): E344-352.

6. Kale AA, Patravale VB. Design and Evaluation of SelfEmulsifying Drug Delivery Systems (SEDDS) of Nimodipine, AAPS PharmSciTech, 2008; 9 (1): 191 196.

7. Kanga BK, Development of self-microemulsifying drug delivery systems (SMEDDS) for oral bioavailability enhancement of simvastatin in beagle dogs, Int. J. Pharm 2004; 274: 65-73.

8. Beg S, Swain S, Singh HP, Patra CN, Bhanoji R ME. Development, Optimization, and Characterization of Solid Self-Nanoemulsifying Drug Delivery Systems of Valsartan Using Porous Carriers, AAPS PharmSciTech. 2012; 13(4): 1416-1427.

9. Nagarsenker MS, Date AA. Design and evaluation of selfnanoemulsifying drug delivery systems (SNEDDS) for Cefpodoxime proxetil. Int. J. Pharm., 2007; 329: 166172.

10. OECD Guidelines for the testing of chemicals, revised draft guidelines 423: Acute Oral toxicity Acute toxic class method, revised document, CPCSEA, Ministry of Social Justice and Empowerment, Govt. of India; 2000.

11. Schurr PE, Schultz JR, Parkinson TM. Triton-induced hyperlipidemia in rats as an animal model for screening hypolipidemic drugs. Lipids, 1972; 7(1): 6874.

12. Norazlinaliza $S$, Mahiran $B$, Basyaruddin AR, Dzulkefly $K$ A, Hamidon B, Abu BS, Phase Behaviour, Formation and Characterization of Palm-Based Esters Nanoemulsion Formulation containing Ibuprofen, Journal of Nanomedic Nanotechnol, 2011; 2 (4): 1-5.

13. Michalets EL. Update: clinically significant cytochrome $P$ 450 drug interactions. Pharmacotherapy, 1998; 18: 84-112.

14. Olsson AG, Pears J, McKellar J, Mizan J, Raza A. Effect of rosuvastatin on low-density lipoprotein cholesterol in patients with hypercholesterolemia. Am. J. Cardiol., 2001; 88, 504-508.

15. Subramanian N, Ray S, Ghosal S, Bhadra R, Moulik SP. Formulation Design of Self-Microemulsifying Drug Delivery Systems for Improved Oral Bioavailability of Celecoxib, Biol. Pharm. Bull., 2004; 27 (12): 19931999. 